\title{
DE JAVIER DE BURGOS A ORTIZ DE ZUNIIGA
}

INICIACION DE LOS ESTUDIOS DE DERECHO ADMINISTRATIVO CON CARÁCTER SISTEMÁTICO EN ESPANA

Con motivo del homenaje que la Facultad de Derecho de la Universidad de Madrid dedicara al que nuestro malogrado Fernández de Velasco llamó "catedrático por antonomasia ejemplar y representativo" don José Gascón y Marín, publiqué un artículo sobre don Francis:o Javier de Burgos y Olmo relatando la vida de tan preclaro representante de la España del pasado siglo, resaltando la influencia que tanto sobre la gente docta como sobre el vulgo ejerció; primero con la "Exposición sobre los males que aquejaban a España y medidas que debia adoptar el Gobierno para "emediarlas", dirigida a Fernando VII desde París en 24 de enero de I826; después con la "Instrucción a los subdelegados de Fomento" (Nuestros artuales Gobernadores) de 30 de noviembre de 1833 y final y principalmente con las conferencias que bajo el título "Ideas de Administración" expuso desde la cátedra del Liceo de Granada en $18_{41}$ ('la primera probablemente debió ser pronunciada en los últimos cías de diciembre de 1840 ), conferencias que no sólo son un intento de ordenación del conteniảo de esa nebulosa que se llama la Administración, sino también del maremagnun de disposiciones que integran la legislación administrativa.

El pueblo español, que ya en el año de 1840 dudaba y hasta renegaba de la política, empezaba a poner sus ilusiones en la eficacia de una Administración que, practicada por personal capa18 citado, le trajese no sólo la paz y buen orden que son base de todo 
bienestar, sino el mismo bienestar y prosperidad en todos los aspectos a que puede tender la humana inclinación.

Los doctos y los que sin título de tal se hallaban al menos iniciados en la orientación que representaba entre nosotros Javier de Burgos, ansiaban igualmente conocer los secretos de esa nueva manera de enfocar los problemas nacionales mediante una selecta Administración.

El mismo Javier de Purgos había declarado repetidamente que de un buen personal y de un personal no sólo rectamente intencionado, sino suficientemente preparado, podría esperarse la ansiała regeneración. Se recordaba cómo cuando fué nombrado ministro una de sus obras principales y de sus más hondas preocupaciones fué la designación de las personas que con el título de Subdelegados de Fomento habrían de ejercer en las provincias que también él creara, y en relación con el Ministro de Fomento, las funciones que éste le encomendara. Se recordaba cómo para el nombramiento de este personal no cuidó de rodearse de los que le siguieran políticamente, sino de los que pudieran dar un mayor rendimiento, no sólo por' su honorable conducta, sino por su competencia en el desempeño de la función que se le encomendara. $Y$ así, no prefirió al noble, al anciano o al adinerado sólo por serlo, sino que desde el anciano venerable al joven de apenas treinta años, desde el título de Castilla al rico propietario o al Magistrado íntegro, donde quiera que encontró a los que por sus méritos consideraba competentes y preparados para ayudarle en la labor que desde el $\mathrm{Mi}$ nisterio él intentaba, les otorgó el nombramiento de Subdelegados de Fomento, y puede decirse sin exageración que en el corto período en que ejercieron sus cargos los Subdelegados por el nombrados causaron más beneficios al pueblo y removieron más obstáculos que después durante muchos años de reformas en los que no se tuvo la preocupaçión de seleccionar el personal conveniente.

Las conferencias pronunciadas en el Liceo de Granada tendian a cumplir como uno de sus fines principales este de iniciar en el conocimiento y adoctrinar en la realización práctica a quienes en el día de mañana hubieran de echar sobre sus hombros la pesada carga de rehacer la vida nacional española valiéndose de una fuєrza que hasta entonces no se había empleado. Esta fuerza es la que Javier de Burgos consideraba necesaria para acabar con los males de España, según había ya indicado el año I826 en la "Exposición" a Fernando VII ; es la fuerza de que intentó valerse el 
año I833 desde el Ministerio de Fomento y que encontró débil y de minúsculos efectos no obstante su celo en la designación de los Sut,delegados. Es la fuerza que creía necesario poner en marcha y a cuyo logro desde su Cátedra del Liceo puso todo el empeño de que él era capaz, preparando el ambiente y estimulando el estudio del Derecho Administrativo; estudio que hasta entonces no había pasado de ser el de conocimiento de una legislación cuyo fárrago trataban de desembrollar los que habían tenido la valentía de adentrarse por entre la complicada serie de textos legales, cuya coordinación y vigencia no era empresa fácil de llevar a la práctica; muv principalmente por faltar un criterio científico según el cual pudiera reducirse a unidad lo vario y a sistema lo que, atendiendo a circunstancias accidentales y de momento, para resolver cuestiones imprevistas, halla solución en una orden en la que la más de las veces era el deseo de favorecer a un particular y no el de cuidar del interés colectivo, lo que había servido de base para su pub'icación. Son realmente numerosos los casos en que la explicación que intente darse a muchos mandatos y a autos acordados del Consejo o providencia de los Corregidores conduce, como dice Oliván, a "suposiciones que excitan la hilaridad". La carencia de fijeza en las reglas que se habían de cumplir llevaba a situaciones como la que refiere el mismo Oliván, del Ayuntamiento de Madrid, sobre alineación de dos casas en una misma calle, de los que en una se resuelve contra el cuerpo municipal, siendo así que tenía razón, y en la otra triunfa, siendo así que no la tenía, o por lo menos no era "la que al público convendría que tuviese".

Desde muy antiguo se había intentado ordenar el material cuyo conocimiento debía servir de base para ejercer sus funciones a los Corregidores, siendo en este sentido la obra del Licenciado Bobadilla verdadero modelo, pues no sólc exponía el orden legal que reputaba vigente, sino que aducía los fundamentos que en la doctrina sagrada y profana podían servir para robustecer el va!or de las decisiones o de las disposiciones del derecho positivo aplicable. Precisamente el citado Bobadilla insistía sobre las condiciones que habian de reunir los que desempeñasen los cargos públicos. Y lo mismo que en Bobadilla, en el Padre Márquez, en Quevedo, en Saavedra Fajardo, en Jovellanos, en Cabarrús y en tantos otros. Pero no son precisamente estos antecedentes los que de momento nos interesan.

20 Lo importante es señalar la necesidad de preparar a quienes 
hayan de poner por obra la Administración del Estado recibiendo las enseñanzas precisas, porque sin este personal apto, aun contando con el más bien intencionado deseo, prácticamente nada se logrará. Esta era la preocupación de Javier de Burgos y en ella le acompañó Ortiz de Zúñiga y después muchos más.

No puedo resistirme a recordar unas apreciaciones de Oliván a este respecto de 1843 , que decía así: "Si los funcionarios de buena intención, de celo y conocimientos pueden adelantar poco en el actual estado de cosas, menos hay que esperar de hombres desprovistos de prendas, desnudos de ciencia, advenedizos en la Administración e injertos en ella por la parcialidad o los amaños a favor de la dislocación general, en que no hay mesura en el pedir ni en el conceder y en que a los más altos puestos de Hacienda y de Cinbernación aspira, y a veces sube, quien para ninguna otra cosa ha parecido bueno ni mediano. De ahí de que en muchas partes no se administra, porque no se sabe lo que es administrar, sino que se manda con violencia, o se pone toda la atención en intrigas políticas; de ahí el figurarse que se cumple maravillosamente con sólo dirigir campanudas y ridículas proclamas donde se echa a lucir la ignorancia; de ahí el contentarse con repetir lo cien veces mandado sin curarse de su complimiento y el trasladar escuetamente las disposiciones superiores a manera de estampilla, sin explicar, sin facilitar la ejecución, sin hacer el menor bien a los pueblos; de ahí, en fin, los abusos y el mal ejemplo. Los buenos empleados vendrán cuando se busquen y abundarán cuando se formev: y cuando observen que se trata seriamente de regenerar la Administración."

Poco, en efecto, hay que esperar de quienes, desnudos de ciencia, son advenedizos en la Administración, porque mal puede admiristrarse quien no sabe que sea la función que debe cumplir.

"Las luces-dice don Manuel Ortiz de Zúñiga refiriéndose al informe de Jovellanos sobre la ley Agraria-que habrá derramado sobre la Nación este inmortal escrito no fueron del todo perdidas, porque ellas iluminaron a la pasada generación e iluminan todavía a la presente..." "Pero el que más ha enriquecido la ciencia de la Administración, el que ha conseguido cimentarla sobre bases fijas, en cuanto es susceptible de ellas, en casi todas las numerosas ramas que la constituyen, es aquel escritor elocuente $\mathbf{y}$ profundo que, ya desde un país extranjero, en la Memoria que dirigió a Fernando VII en 1826 , ya descle la altura de su Ministe- 21 
rio en 18.33 y ya asimismo desde una Cátedra del Liceo de Granarla, ha legado un tesoro a la generación presente y a las venideras."

Más adelante dice: "Ni aún tenemos tratados de Derecho administrativo, esto es, la explicación de la parte dispositiva de los principios y doctrinas adoptados por las leyes y erigidos en preceptos..." "Apenas si hay quien se dedique a publicar obras literarias sobre materias administrativas, no obstante la abundancia que hay en F.spaña de esclarecidos escritores. Por otra parte, no parace posible ocuparse en tan temerario empeño cuando difícilmente y sólo a fuerza de penoso estudio se consigue saber qué leyes rigen... en medio del confuso laberinto que forma una legislación productó del régimen abolido y de las recientes innovaciones."

Pero siendo necesario conoser el régimen administrativo español en esta época para que los que lo habian de poner en práctica lo hicieran con arierto y no caprichosamente, el Gobierno, recogiendo la semilla que arrojara Javier de Burgos, estableció en las Universidades Cátedras de Derecho administrativo para la explicación y conocimiento de las leyes que corresponden a esta materia, naciendo aquí, según nos dice el mismo Ortiz de Zúñiga, la necesidad de publicar tratados elementales de Derecho administrativo para auxilio de los profesores y de los mismos alumnes. Las dificultades que presenta una labor de este género los ve claramente Ortiz de Zúñiga, pero hay que intentar vencerlos, porque siempre será preferible un Tratado, aun cuando sea imperfecto. a carecer de él, dejando la materia administrativa, y sobre todo a los que la han de practicar, "sumidos en la oscuridad y la cenfusión".

Por ello se decide a publicar sus elementos de Derecho administrativo, proponiéndose "no salir de los límites de un mero expositor de las doctrinas, aunque procurando presentarlo con el orden y método que en vano se aspiraría a encontrar en las compilaciones legales. "No voy, pues, a crear una ciencia-dice Ortiz de Zúñiga-; tampoco intento profundizar en su filosofía; ni elevarme a la región de las teorias controvertibles, a los principios incuestionables. Mi propósito es muy limitado. Yo acepto la Legislación administrativa tal cual hoy existe, cual hoy rige en España, con sus pocos aciertos, con sus innumerables errores; pero, sin embargo, procuraré coordinar sus partes, metodizar su estudio, 22 dar alguna claridad a ese caos a cuya vista se arredra el espíritu 
más tenaz y perseverante; y alguna vez me será forzoso indicar los defectos de las leyes poco acordes con los principios constituitivos de nuestra sociedad y con las doctrinas más acreditadas de la Administración."

Es decir, su propósito es realizar una ordenación de la legislación administrativa española en la que la claridad sustituya al caos, y, además, criticará los defectos de las leyes que no estén conformes con las doctrinas más acreditadas sobre lo que sea la Administración. Va a abrir un camino del todo nuevo y desconocido y otros autores más hábiles perfeccionarán la obra para cuyos cimientos coloca la primera piedra.

$Y$, en efecto, así es. Los "Flementos de Derecho administrativo", de Ortiz de Zúñiga, son el primer intento de exposición sistemática del Derecho administrativo en España, y así como de Javier de Burgos puede decirse que fué el animador del Derecho administrativo en España durante la primera mitad del siglo XIX y quien dió la voz de alerta sobre las excelencias de la Administración, culminando en sus lecciones del Liceo de Granada la más armónica exposición de su contenido, así también fué en Granada, en la librería de Sanz, en la calle de la Monterería, en I842-43, esto es, un año inmediatamente después de pronunciadas las lecciones del Liceo por Javier de Burgos, donde se publicó el primer ensayo de sistematización del Derecho administrativo español.

No son los "Elementos de Derecho administrativo" una obra perfecta, mas esto no importa; Ortiz de Zúñiga colocó "la primera piedra", según él mismo nos dice, de la obra que era necesario realizar para bien de multitud de hombres públicos "y de ciudadanos que a cada paso han menester de una guía que les conduzca al conocimiento de sus derechos y de sus obligaciones".

$\therefore$ Es que no eran suficientes las compilaciones del Derecho positivo que se estimaba vigente? ¿Es que "El libro de los Alcaldes y Ayuntamientos", del mismo Ortiz de Zúñiga, no bastaba para satisfacer aquellas necesidades? Ciertamente que no, y este fué el fruto que Ortiz de Zúñiga obtuvo de la labor realizada por Javier de Burgos. Había que sistematizar el material legislativo, y para este propósito Ortiz de Zúñiga no encontró mejor guía que el "Memorial a Fernando VII", la "Instrucción a los Subdelegados de Fomento", las lecciones del Liceo de Granada y las conversaciones con aquel socio del Liceo que siempre estaba dispuesto a trans- 
mitir a los demás su saber y su experiencia sobre cuestiones administrativas.

En el año i 84 I concurrían a las clases del Liceo y a la tertulia de Javier de Burgos, entre otros, Ortiz de Zúñiga y Oliván; éste, fuertemente preocupado con los problemas de la elaboración de la ciencia de la Administración; aquél, preosupado con el grave problema de ordenación según criterio científico del derecho positivo vigente. Por ello Fernández de Velasco dice, con razón, refiriéndose a esta época que la tendencia general era sistematizar nuestra legislación, salvo en Oliván, donde se señala un aspecto crítico y constructivo, hasta llegar a Colmeiro, que es el más innovador, siendo aun hoy su obra "Derecho administrativo español", pubiicada en 1850 , digna de ser consultada con detenimiento.

La obra de Ortiz de 7úñniga "Elementos de Derecho administrativo" consta de tres volúmenes, publicados en I 842 el primero y en 1843 el segundo y tercero.

El volumen primero está dedicado a "La organización administrativa"; el segundo y tercero, a "Los objetos y atribuciones de la Administración".

Lo más interesante de toda la obra es la lección primera del volumen primero y la undécima del tercero.

La lección primera de la parte primera se titula "Idea general de la Administración y del Derecho administrativo", y en ella no sólo se exponen las ideas fundamentales de la Administracién como Poder o elemento de gobierno, sino los de la Administración como ciencia y después la del Derecho administrativo.

Aunque cita a Guizot y a Escriche, bien pronto se echa de ver que es Javier de Burgos quien le sirve de inspirador, pues si bien cita a algún otro escritor, como, por ejemplo, a Silvela, es sólo por cuanto Silvela se ocupa de Javier de Burgos, y recogiendo doctrina de éste determina la índole, naturaleza y objetos de la Administración conisiderada como Poder que tiene acción y da impulso a cuanto existe en la sociedad, promoviendo la prosperidad, protegiendo los intereses generales y, en una palabra, haciendo el bien como su incumbencia, su esencia y su objeto exclusivo.

Para dar cuenta de los fines de la Administración, reproduce la doctrina expuesta por Javier de Burgos en el Liceo: "La Administración-dice-preside el movimiento de la máquina social, precipita o modera su acción, arregla o modifica su mecanismc y 24 protege así y conserva o mejora todos los intereses públicos. Ob- 
jeto es de su solicitud el hombre antes de nacer y lo es después que ha dejado de existir...", etc., texto éste que copian todos los escritores de la época y reproducen los posteriores; hablando como Javier de Burgos de la inmensidad y de su omnipresencia, por lo que precisa organizar convenientemente la Administración para que en todo momento llegue allí donde debe realizar su función bienhechora.

Expuesto lo que sea la Administración como Poder, nos habla luego de la Administración como Ciencia, apoyándose igualmente en Javier de Burgos y afirmando que recoge de la experiencia de los siglos aquellas reglas que revelan los medios de organizar la sociedad y mantener las relaciones entre la generalidad y los individuos. Pero sus principios, según Ortiz de Zúñiga, son variables, dependiendo de circunstancias alterables y transitorias (en contra de la opinión, que cita, de Bonnin, según el cual se compone de principios universales e invariables); doctrina ésta que Ortiz de Zúñiga califica de exageración disculpable. Lo cual no es obstáculo para que aconseje no se abandone el estudio de la Ciencia de la Administración, a pesar de la gran dificultad que supone el llegar a producir un libro en el que se pueda aprender fundamentalmente lo que hay que saber acerca de ello.

Mucho más fácil que el camino a seguir para conocer la Ciencia de la Administración es el que nos conduce al conocimiento del Derecho administrativo; tiene éste por objeto las doctrinas que emanan de las leyes y disposiciones relativas a la Administración, así romo el Derecho civil se ocupa de las leyes y disposiciones civiles. Para fijar la diferencia de unas y otras Ortiz de Zúñiga reproduce un pasaje de la "Exposición" de Burgos a Fernando VII, y aun cuando nos dice que no puede exponerse la distinción con más claridad de lo que hace Javier de Burgos, él mismo trata de aclarar lo que sin duda no lo está tanto con diversos ejemplos, que dejan la cuestión en el mismo estado. Al exponer estos casos deriva hacia otro tema muy interesante $\mathrm{y}$ es el de determinar como contenido de la legislación administrativa, no solamente las leyes propiamente dichas, sino, además, los reglamentos de gobierno y las disposiciones de los agentes de la acción central, de los Jefes y Corporaciones de la Administración en las provincias, las ordenanzas municipales y los acuerdos o bandos de buen gobierno. Todo este cuerpo de disposiciones, que emanan de tan diversos orígenes, constituyen para Ortiz de Zúñiga el Derecho administrativo. 
Como antes dejo dicho, la obra de Ortiz de Zúñiga no es, ni mucho menos, perfecta; al recordarla lo hacemos para hacer constar es el primer intento en España de exposición sistemática del Derecho administrativo.

Después de indicar lo que el. Derecho administrativo sea a diferencia de la Administración como Poder y como Ciencia, en la lección segunda da una "idea general de la organización administrativa", hablando del territorio y su división y después de los "agentes de la Administración", que se dividen en Central, Provincial y Local, y como el Consejero de la Corona que se tituia Ministro de la Gobernación es imposible que por sí solo pueda dar impulso a toda la complicada máquina de la Administración púbiica, sin otros Jefes subordinados al mismo y superiores a los de las provincias, de aquí la necesidad de las Direcciones Generales, que, con los Jefes Políticos, Diputaciones, Juntas y Comisiones establecidas en las capitales de provincia y los Alcaldes, Ayuntamientos, Comisiones y Juntas Municipales, integran la organización administrativa del pueblo español.

Como se ve, todo queda reducido a la labor del Ministro de la Gobernación y de los Subdelegados de Fomento y Alcaldes; es decir, a exponer aquellas instituciones que habían sido más particularmente tratadas por Javier de Burgos.

Después expone la organización de la Administración Central, que concentra en el Ministerio de la Gobernación, el cual "personifica la Administración" y al que, por consiguiente incumbe la vigilancia suprema sobre casi todas las ramas en que aquélla ejerce su influencia protectora. Este Ministerio debe ser, según frase de Javier de Burgos, "el taller de la prosperidad nacional", y el Mínistro, "el primer guardián del orden público y el primer agente de la prosperidad nacional".

Que Javier de Burgos hablase en estos términos de un Ministerio por cuya creación venía trabajando desde la publicación del Memorial a Fernando VII se explica perfectamente. Lo que no se explica tan aínas es que Ortiz de Zúñiga no pare de repetir lo que Javier de Burgos dijera.

Expone luego la Administración Provincial, y, recogiendo apreciaciones de Javier de Burgos, desarrolla la teoría según la que siendo el Ministro de la Gobernación quien dirige e impulsa la Administración, pero no quien administra, pues ésta es atribut26 ción de los encargados bajo su inspección, de la aplicación de las 
leyes y reglamentos administrativos o las necesidades locales; trata de los Jefes políticos, que son, en sus respectivas provincias, los "Jefes superiores de todas las ramas de la Administración pública. siendo de lamentar que para el ejercicio de este cargo no se exija ningún título de saber, ni de capacidad. Aparte de esta juiciosa censura, expone luego una doctrina muy interesante con respecto a la discrecionalidad con que deben actuar en todos los casos en que la ley expresamente no se lo prohiba, estando obligados estrictamente a ejecutar cuanto crean que conduce a la prosperidad y ventura de los habitantes del término que les está confiado. Como se ve, Ortiz de Zúñiga no se aparta en nada de las normas que había señalado Javier de Burgos.

$\mathrm{Y}$ lo mismo sucede cuando expone la Administración municipal, dando al cargo de Alcalde un relieve e importancia dentro del Municipio igual al del Tefe político en la provincia, con lo que repite la doctrina de Javier de Burgos, que había dicho que "el dogma gubernativo de la unidad exige que, así como no hay o no debe haber más que un administrador supremo para el Estado, uno sitperior para cada provincia y uno subalterno para cada distrito, no haya más que uno local para cada pueblo. Este Administrador es el Alcalde".

El resto de la materia expuesta en esta lección $\mathrm{V}$, así como en las anteriores, no es sino una transcripción del derecho vigente en España al modo como lo había hecho en su obra el "Libro de los Alcaldes", terminando el volumen primero con una lección sexta sobre "Comunicación y publicación de las leyes y disposiciones generales".

Todo el tomo segundo y casi todo el tercero están dedicados a exponer "los objetos y atribuciones de la Administración (ias siete lecciones de que consta el segundo y diez de las once del tercero).

Sara vez se logra con estas lecciones reducir a principios $\mathrm{v}$ ordenar según ellos los distintos objetos que persigue la Adminisción. Se nota, como latiendo, en el propósito ordenador el recuerdo de la "Instrucción" dirigida a los Subdelegados de Fomento por Javier de Burgos; pero, como nos dice Ortiz de Zúñiga, no siempre es fácil separar lo que es objeto de la Administración de lo que es objeto del poder judicial, or:ginándose aquí la confusión en cuanto a las respectivas competencias de la Administración y de los Tribunales. No expone Ortiz de Zúñiga, al tratar 
de cada uno de los objetos de la Administración, los límites propios de ésta y de la autoridad judicial, ni aun siquiera los puntos de contacto entre una y otra autoridad administrativa y judicial, y por ello ofrece marcado interés el contenido de la lección i I del tomo tercero, donde se trata de precisar que sea lo administrativo, a diferencia de lo civil o contencioso, lo que por participar de ambas cualidades puede calificarse de contencioso-administratiz'o; lo que siendo de la competencia de la Administración sirve de base a una intervención judicial o cuestiones prejudiciales. Y los verdaderos conflictos o competencias de facultades, que son siempre inevitables, y que precisan un poder supremo que irrevocab!emente resuelva sobre estas cuestiones de jurisdicción.

Ciertamente que, como indicaré, extractado, el contenido de esta lección II, no se resuelven con claridad estos problemas por parte de Ortiz de Zúñiga; pero sólo el hecho de haberlos visto $\mathrm{y}$ el haber intentado solucionarlos constituye un mérito $\mathrm{y}$ un atrevimiento al que no cabe regatear el debido aplauso.

Después de establecer la distinción entre los poderes legislativo, ejecutivo y judicial, al deslindar las atribuciones de la Aclministración y la Justicia, según las doctrinas legales, establece las siguientes reglas: I. $\mathrm{E}$ - poder judicial no puede ocuparse más que en los negocios contenciosos o civiles; 2. $\stackrel{\text { a }}{\text { La Administración }}$ sólo puede mezclarse en asuntos gubernativos o administratizns; 3. - Cuando se confunde la naturaleza de las materias y participan a un tiempo de ambas cualidades, los objetos en que entiende la autoridad pública son contencioso-administrativos; 4. a En muchos casos el conocimiento de un asunto corresponde a la Administración, y por incidencia a los Tribunales civiles, sin que mutuamente puedan obstruirse el ejercicio de sus funciones respec-

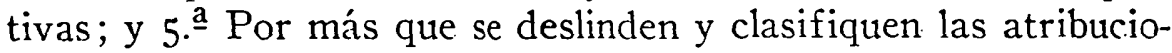
nes de ambos poderes son siempre inevitables los conflictos $y$ competencias, y precisa un poder supremo que los resuelva.

Desarrollando estas reglas, nos dice, es muy difícil establecer un deslinde entre lo judicial y lo administrativo, lo cual no es obstáculo para que inmediatamente después establezca la regla de que cuando se ejercita una acción legal que trasfiere derechos y constituye obligaciones, materia ésta que con tanta claridad se aprende en los elementos de la jurisprudencia común, el conocimiento de estos asuntos tienen el carácter de contencioso 28 y corresponden a la jurisdicción civil. Esto es verdaderamente 
ingenuo, y mucho más lo que dice a continuación. Todos los negocios que no han llegado a la esfera de contencioso porque no pueden ser "promovidos en virtud de alguna de las acciones i-iviles", son asuntos gubernativos o administrativos. Establece luego la limitarión que supone el no poder entablar interdictos contra las providencias de los Ayuntamientos y Diputaciones en los negocios que pertenecen a sus atribuciones. Después señala la diferencia entre los asuntos administrativos y criminales, y nos quedamos, en fin de cuentas, con el conocimiento que nos proporcionan los tratados de jurisprudencia civil para resolver que son asuntos civiles todos aquellos que como tales son defit:iclos por los civilistas, por tener una acción legal que poder ejercitar.

Hay, además, asuntos que siendo contenciosos-civiles-por su naturaleza, son a su vez administrativos por el carázter de su objeto y por las circunstancias de los que en ellos tienen interés. Estos asuntos son los que él denomina contencioso-administrativos, y su deslinde of rece serias dificultades, dando como norma para resolverlos el de que interesen a la sociedad o a una parte cole stiva de sus individuos.

De todos modos la dificultad nacerá al intentar resolver quién sea la autoridad que deba conocer de estos asuntos o el 'Tribunal que deba resolverlos, pues no existiendo tribunales mixtos contencioso-administrativos, ocurrirá que Justicia y Administración entren en cuestiones de competencia cuyos trámites "no están prescritos por la ley y cuya decisión es a veces desacertada y por lo común lenta y tardía".

Otros asuntos hay en los que intervienen Justicia y Administración, pero sin estorbarse, con completa independencia. Es el casc de las decisiones prejudiciales. Pero en multitud de ocasions el deslinde entre lo judicial y lo administrativo no es posible establecerlo, surgiendo las cuestiones de competencia que debían resolverse, según Ortiz de Zúñiga, con audiencia del Consejo de Estado, por el Rey, con la responsabilidad de sus Ministros.

Estas son las reg'as propuestas por Ortiz de Zúñiga, que "dis$\tan$ mucho de la exactitud, y que ciertamente no bastan para evitar y dar cumplida solución a las cuestiones que diariamente se controvierten en el Foro y ante las autoridades y corporaciones administrativas"; pero en tanto una nueva ley no se estabjezca, "seria aventurado proponer otras doctrinas, aunque éstas estuviesen apoyadas en las buenas teorias de la Administración, por- 29 
que no tendrán la sanción legal del Derecho Administrativo", dice Ortiz de Zúñiga.

I_as leyes de 2 de abril y 6 de septiembre de I 845 que organizan, respectivamente, los Consejos Provinciales y Consejo Real seguirán esta ruta.

Esto es lo que he considerado más importante de referir para señalar el hecho de la aparición de la primera obra que con carácter sistemático trata de exponer entre nosotros el contenilo de un Derecho como el Administrativo, que tiende a elevarse de la vaguedad de unas aspiraciones rellenas de esperanzas a una protección eficaz de los intereses de los administrados y de la misma Administración.

Antonio Mesa Segura 